\title{
Pattern of Five-Year Weight Change by Age and Birth Cohorts in a Swedish Adult Population
}

\author{
Faisal Al-Emrani ${ }^{1, *,}$, Martin Stafström ${ }^{1, \S}$, Jonas Björk $^{2, \S}$ and Per-Olof Östergren ${ }^{1, \S}$ \\ ${ }^{1}$ Lund University, Social Medicine and Global Health, Department of Clinical Sciences Malmö, Clinical Research Cen- \\ tre, S-205 02 Malmö, Sweden; ${ }^{2}$ Lund University, Division of Occupational and Environmental Medicine
}

\begin{abstract}
The driving factors behind the global epidemic of obesity have not yet been fully elucidated. Investigating the effect of age and cohort on weight change might enable us to develop effective intervention strategies.

Aims To analyse the pattern of BMI change by age and birth cohort over five-year follow-up in adult Swedish sample.

Methods The data was drawn from the Scania Public Health Cohort. The baseline survey was conducted between 1999 and 2000, and the follow-up in 2005. A total of 10,373 individuals responded to both surveys; all were included in the present study. The data was stratified into three-year intervals according to a respondent's birth year and age at baseline. This was done in order to allow for age and cohort effect analysis by means of fixed effects linear mixed models.

Results We observed a significant increase in BMI between baseline and follow-up for males and females $(p<0.001)$, as well as significant age and cohort effects resulted from age-period and cohort-period models, respectively, for both genders. The age effect on BMI varied between -1.94 to +1.10 BMI units among males and -3.15 to +0.54 among females. The cohort effect on BMI varied from -1.67 to +1.61 BMI units in males, and from -2.28 to +1.18 in females.

Conclusions Our analyses suggest that cohort effects play a contributory role in obesity. Our results also show that it is difficult to distinguish between age-period and cohort-period effects in our study, due to on the one hand the linear relationship between age, period and cohort, and on the other hand to a short follow-up.
\end{abstract}

Keywords: Age effect, cohort effect, BMI change, BMI gain, overweight, obesity, Sweden.

\section{INTRODUCTION}

Overweight and obesity are on the rise globally; the Scandinavian countries are no exception $[1,2]$. High body mass index (BMI) has been shown to be a major risk factor for an array of chronic illnesses, such as hypertension, diabetes, musculoskeletal disorders, and some types of cancer [3]. In 2004, overweight and obesity contributed 5\% to the global burden of disease in terms of Disability Adjusted Life Years (DALY) [4].

The current epidemic of overweight and obesity has a great number of determinants, e.g., diet [5], lifestyle [6], technical innovations [7], socioeconomic status $[8,9]$ level of education $[10,11]$, physical inactivity $[12,13]$, and gender [14]. It has been suggested that epigenetic factors also have an impact on BMI. The latter claim is based on the hypothesis that inadequate nutrition during pregnancy switches on genes in the offspring that determine the rate of fat accumulation, even in periods when access to food is unrestricted. It has been postulated that this effect might persist for over a generation $[15,16]$. Such a hypothesis could

\footnotetext{
*Address correspondence to this author at the Lund University, Social Medicine and Global Health, Department of Clinical Sciences Malmö, Clinical Research Centre, S-205 02 Malmö, Sweden; Tel: (+46)40 391408; Fax: (+46)40 391333; Email: Faisal.al-emrani@med.lu.se

${ }^{\S}$ These authors contributed equally to this work
}

explain why immigrants especially those from low-income countries have a greater risk of developing obesity than the high-income indigenous population of their adoptive home [17].

The mechanisms cited above might affect weight gain over the life cycle of an individual, or could be manifestations of changes in the environment during a specific time period, e.g., when economic policies modify the cost and availability of food. Additional factors may only affect certain cohorts of individuals, depending on eating habits, food preferences, or the epigenetic possibility mentioned. These effects require different intervention strategies. Therefore, it would be useful to better understand the role of each element in the overweight epidemic. Combinations of factors could also be expected to vary considerably by geographical location and between different sub-groups of a given population over time.

The temporal effects on trends of weight change are of great relevance in a health equity perspective. Previous researchers have acknowledged this situation and focused on the following elements: (a) age effects (variation due to physical and social life changes), (b) period effects (variation over time due to environmental factors), and (c) birth cohort effects (variations attributable to exposures during pregnancy or early childhood that are sustained over the course of a life span). The three factors are collectively known as APC effects [18]. 
Attempts have been made since the mid-1970s to model these effects for various health problems (e.g., smoking and cancer), both in the way they are differentiated and how they interact [19-21]. In a repeated cross-sectional study among Australian adults, birth cohort affiliation was significantly associated with the prevalence of overweight. The effect was more obvious among those born since 1960 than for those born earlier [22]. Another repeated cross-sectional study in the US indicated that one's birth cohort significantly influenced the odds ratio of obesity, since BMI increased in every five-year period between 1976 and 2001 [23].

Several longitudinal studies from the US, Denmark, Korea, and The Netherlands detected period and cohort effects on BMI change and obesity prevalence in all study contexts. Olsen et al. found that the obesity epidemic in Denmark has grown in phases [24]. An increase was identified for birth cohorts from the early 1940s to the mid-1950s, and from the late 1960s onward. A recent Korean investigation concluded that there are period and cohort effects for diabetes as well as obesity. The effect, however, was less pronounced in the case of diabetes [25]. Continuing research on the overweight and obesity epidemic suggests that data on period and birth cohort effects have had little impact on the search for the cause of this global issue. Intervention strategies appear to be even less affected by such findings, although studies taking period and birth cohort effects into account have shown their substantial influence.

The present paper seeks to investigate the pattern of BMI change by age and birth cohort over five-year follow-up in adult Swedish sample: the Scania Public Health Cohort (SPHC).

To the best of our knowledge, ours is the first study to apply this strategy to a Swedish population sample. We believe the results will focus the attention of decision makers and health policy planners on less acknowledged causes, thereby allowing them to intervene at the family, society, or national level and better address the equity aspect of the overweight epidemic.

\section{METHODS}

\section{Population and Instrument}

The data set of this study is derived from two surveys: the 1999 baseline assessment and 2005 follow-up SPHC questionnaire distributed to a representative sample of the general population in Scania, Sweden's southernmost county.

In $1999,24,922$ males and females ages 18 to 80 were randomly selected within a non-proportional geographically stratified sample. The stratification was done by a random selection from each of the 60 administrative units in the county of Scania. A questionnaire was mailed to these individuals, and their responses were collected between November 1999 and April 2000. After three reminders, 13,604 (59\%) had responded to the survey. In 2005, the same questionnaire was again mailed to those who had completed it in 1999. This time a total of $10,485(77 \%)$ responded. However, due to incomplete or questionable data (such as missing height or weight, or a large discrepancy in the height reported in the two surveys), 102 people were excluded. The final cohort was comprised of 10,373 individuals, of whom 4,584 (43.8\%) were males and 5,789 (55.3\%) females.

The SPHC questionnaire had 12 sub-sections covering a wide range of issues, including self-rated health, health care utilization, environmental and occupational factors, healthrelated behaviours, and socio-demographic information. A fuller description of SPHC may be found in [43].

\section{Measurements}

Height and weight were self-reported and specified in the questionnaire as "height (in cms) without shoes" and "weight (in kgs) without clothing". BMI was calculated by dividing weight in kilograms by height in squared meters $\left(\mathrm{kg} / \mathrm{m}^{2}\right)$.

Overweight and obesity were defined according to World Health Organization standards as overweight $=$ BMI 25.00 to $29.99 \mathrm{~kg} / \mathrm{m}^{2}$, and obesity $=\mathrm{BMI} \geq 30 \mathrm{~kg} / \mathrm{m}^{2}[3]$.

Age was established by means of the official Swedish population register.

\section{Statistical Analysis}

Analyses were performed using Predictive Analytics Software (PASW) 18.0 for Windows with a 5\% level of significance.

\section{Dependent Variables}

Birth cohorts were defined by year of birth in three-year intervals. Respondents were subsequently classified into 21 birth cohorts. At the same time, 21 age groups were formed, by stratifying the respondent's age into three year interval. The age and cohort effects on BMI change between baseline and follow-up were estimated using linear mixed models (LMM). The cohort-period (CP) and age-period (AP) models have been fitted to the data analysis with the baseline period and oldest birth cohort, and oldest age group, respectively, as reference. BMI, as a repeated measure, was analysed as the dependent variable, while birth cohorts or age groups, and year of analysis (1999/2000 and 2005) were added as fixed factors and fitted into the LMM with a $95 \%$ confidence interval. The same strategy was then used to evaluate the AP effects. We also analyzed the interaction between birth cohort and period \& between age and period using the same models.

\section{Ethical Statement}

This research has been carried out in accordance to the Helsinki Declaration of research ethics regarding human subjects. Both assessments of the cohort have been approved by the regional Research Ethics Committee in Lund University (D nr 1999-99 and 2005-471).

\section{RESULTS}

The proportion of overweight and obese individuals in the study population increased between the baseline and follow-up surveys. The prevalence of overweight rose among males from $43.3 \%$ to $45.1 \%$, and among females from $27.5 \%$ to $29.5 \%$. At the same time, the prevalence of obesity went from $10.2 \%$ to $12.5 \%$ among males and from $9.6 \%$ to $12.6 \%$ 
among females. The increase in overweight was significant for both sexes, while the change in obesity was only significant for females $(p=0.037)$ (Table 1).

We also analyzed the change of mean BMI by gender and found that mean weight had increased significantly over the five years surveyed. Mean BMI increased from 25.7 to 26.1 among males and from 24.5 to 25.0 among females. This increase in BMI was generally significant when we stratified the sample based on three-year birth cohorts, with the exception of the oldest birth cohorts, where decreases or no changes in BMI were noted (Table 2).

The cohort effects, resulted from cohort period models, i.e., the variability in BMI across birth cohorts adjusted for the period effect, ranged from $-1.19 \mathrm{BMI}$ units among males born from 1979 to 1981 , to +1.84 for males born from 1937 to 1939. In females the cohort effects ranged from -1.63 among women born from 1979 to 1981 , to +1.48 among women born from 1934 to 1936 . The age effects resulted from age period model show, overall, similar variability. (See Table 3).

Results from interaction models suggested that the change in BMI between baseline and follow-up differs depending on birth cohort among both males and females in the cohort-period model ( $<<0.001$ for both interactions). In the age-period model the change in BMI differs depending on age among females ( $\mathrm{p}=0.001$ for interaction), but apparently not significantly among males $(\mathrm{p}=0.28)$.

In (Figs. 1 and 2) we plotted the cohort- and age-specific changes in BMI between baseline and follow up for each three-year-interval birth cohort and age group (BMI change and $95 \% \mathrm{CI}$ ) stratified by gender. The cohort-specific changes in BMI seemed to follow a linear trend among both males and females, with the clear increase in BMI observed among the youngest birth cohorts gradually declining and eventually becoming negative among the older cohorts. The age-specific changes in BMI was positive for most age groups among both males and females, suggesting that study participants of the same age generally had higher BMI at the follow up than at baseline, but with no consistent trend across the age groups.

\section{DISCUSSION}

Our findings show that mean BMI increased in the population studied between 1999/2000 and 2005, which could be due to period, age or cohort effect.
Results from cohort-period and age-period models have shown BMI change in both males and females in nearly all the cohorts and age groups studied; increase in younger and middle ages and decline in older segments of the population. Some birth cohorts and age groups showed a greater increase in BMI than others, both in males and females. For example, the male cohorts born in 1928 to 1933 showed a smaller weight gain compared with the cohorts born immediately before and after. The explanation for these discrepancies in the BMI scores across birth cohorts between baseline and follow-up might be related to events that have happened in early life.

Overall, the age effects show a similar pattern with the cohort effects, that make it difficult to distinguish between age-period and cohort-period effects in our study, due to on the one hand the linear relationship between age, period and cohort, and on the other hand to short follow-up.

The interaction analyses in both models (cohort-period and age-period) have shown a significant BMI change depending on birth cohort for both genders while with age only among females, which indicated that the effect of period is more pronounce among females than males.

As with many other countries in the Organisation for Economic Cooperation and Development (OECD), Sweden has seen a rapid increase of overweight and obesity in the general population over the past three decades. It is estimated that the prevalence of obesity in adults has doubled within the last twenty years, and is now approximately $10 \%$ in males and females [26, 27]. Our findings suggest that these figures have already been exceeded.

The results presented here are similar to those found in Denmark [28], Norway [29], Finland [30], France [31], Australia [22,32], and the US [32]. There is agreement that weight increases throughout the life course until about age 60. A stable pattern in birth cohorts between baseline and follow-up has also been demonstrated by these studies. However, our findings suggest that female birth cohorts followed a different pattern that has not been substantiated by other research.

We began at baseline with a relatively large proportion of subjects above age 65 and noted how their BMI score between baseline and follow-up tended to decrease. We assume that this was mainly the result of physiological

Table 1. Descriptive Data of the Sample: ( $n$ and \%), Prevalence of Overweight, and Obesity (Stratified by Gender)

\begin{tabular}{|c|c|c|c|c|c|c|}
\hline & & \multicolumn{2}{|c|}{1999} & \multicolumn{2}{|c|}{2005} & P valu \\
\hline \multicolumn{2}{|c|}{ Females } & 5789 & 55.3 & 5528 & 55.9 & 0.984 \\
\hline Overweight & Males & 1985 & 43.3 & 2060 & 45.1 & 0.000 \\
\hline \multirow{2}{*}{ Obesity } & Males & 466 & 10.2 & 575 & 12.5 & 0.581 \\
\hline & Females & 558 & 09.6 & 728 & 12.6 & 0.037 \\
\hline
\end{tabular}


Table 2. Crude Difference in BMI Between Baseline and Follow-Up; Mean, Standard Deviation, BMI Difference, and t-test, Categorized by Gender and Three-Year Birth Cohort Interval

\begin{tabular}{|c|c|c|c|c|c|c|c|c|c|c|c|c|}
\hline $\begin{array}{c}\text { Birth } \\
\text { Cohorts }\end{array}$ & $\begin{array}{c}\text { Mean } \\
\text { BMI } 99\end{array}$ & SD & $\begin{array}{c}\text { Mean } \\
\text { BM 05 }\end{array}$ & SD & $\begin{array}{c}\text { BMI } \\
\text { change }\end{array}$ & $p$ value & $\begin{array}{c}\text { Mean } \\
\text { BMI } 99\end{array}$ & SD & $\begin{array}{c}\text { Mean } \\
\text { BMI } 05\end{array}$ & SD & $\begin{array}{c}\text { BMI } \\
\text { change }\end{array}$ & $p$ value \\
\hline 1979-1981 & 22.68 & 2.96 & 24.00 & 3.14 & 1.32 & 0.00 & 22.03 & 3.15 & 23.38 & 4.24 & 1.35 & 0.00 \\
\hline 1976-1978 & 23.98 & 3.80 & 25.38 & 4.19 & 1.40 & 0.00 & 22.56 & 3.50 & 23.50 & 4.09 & 0.94 & 0.00 \\
\hline $1970-1972$ & 25.36 & 3.81 & 26.33 & 4.08 & 0.97 & 0.00 & 23.44 & 4.05 & 24.29 & 4.47 & 0.85 & 0.00 \\
\hline 1967-1969 & 25.69 & 3.81 & 26.49 & 4.12 & 0.80 & 0.03 & 23.70 & 4.02 & 24.47 & 4.46 & 0.78 & 0.30 \\
\hline 1964-1966 & 25.59 & 3.44 & 26.35 & 3.86 & 0.75 & 0.38 & 24.04 & 4.09 & 24.96 & 4.71 & 0.91 & 0.18 \\
\hline $1955-1957$ & 25.64 & 3.20 & 26.28 & 3.43 & 0.64 & 0.00 & 24.04 & 3.66 & 24.96 & 4.01 & 0.92 & 0.00 \\
\hline $1952-1954$ & 25.79 & 3.32 & 26.25 & 3.48 & 0.46 & 0.00 & 24.40 & 3.80 & 25.06 & 4.21 & 0.66 & 0.00 \\
\hline 1949-1951 & 25.99 & 3.56 & 26.34 & 3.48 & 0.35 & 0.00 & 24.56 & 4.14 & 24.99 & 4.45 & 0.42 & 0.00 \\
\hline $1946-1948$ & 26.10 & 3.30 & 26.40 & 3.59 & 0.30 & 0.00 & 25.18 & 4.09 & 25.60 & 4.50 & 0.42 & 0.00 \\
\hline $1943-1945$ & 26.04 & 3.58 & 26.30 & 3.66 & 0.25 & 0.02 & 24.78 & 4.26 & 25.13 & 4.43 & 0.35 & 0.00 \\
\hline $1940-1942$ & 26.29 & 3.00 & 26.46 & 3.20 & 0.17 & 0.10 & 24.97 & 3.54 & 25.42 & 3.99 & 0.45 & 0.00 \\
\hline $1937-1939$ & 26.55 & 3.28 & 26.75 & 3.65 & 0.21 & 0.07 & 25.49 & 3.48 & 25.79 & 4.07 & 0.30 & 0.01 \\
\hline 1919-1921 & 25.20 & 2.97 & 24.52 & 3.03 & -0.69 & 0.00 & 24.93 & 3.66 & 24.07 & 4.21 & -0.87 & 0.00 \\
\hline
\end{tabular}

aging, as the birth cohort effects were positive. If weight gain were also found among older age groups, it would most likely lead to a heavier burden on the health system, e.g., increased orthopaedic and diabetes health care needs. The decline of BMI in older cohorts could be related to behavioural and physiological changes within individuals, such as a decrease in energy requirements at rest with advancing years [33]. An increase in weight among younger cohorts and a decrease among older ones is a common finding [34-36]. However, a Dutch longitudinal cohort study reported weight gain among individuals over 60 years of age as well [37].

Several studies have attempted to explain the underlying mechanisms for the discrepancy in weight gain observed among different birth cohort groups. Recent publications on obesity have suggested several factors: changes in the global food system, low caloric energy expenditure due to modern technology, and individual factors, including genetic effects that result from interaction with the local environment. These might account for the variability in body size between individuals $[38,39]$. However, why one gains more BMI units at young age is not clear.

Previous investigations have found it likely to be related to low physical activity. For example, a recent Australian study found that younger birth cohorts of males tended to engage in less leisure time physical activity than older generations [22].

Fast food consumption on a regular basis may be another factor in obesity [40]. Industrial development may be responsible for an increase in energy intake, a diet of lowquality carbohydrates and fats, and a decline in physical activity. This implies that a general change in living conditions plays an important role in the present epidemic of obesity [41]. 
Table 3. Cohort and Age Effects Resulted from (Cohort-Period and Age-Period Models) of Linear Mixed Analyses, Categorized by 3-Year Birth Cohort and Age Groups for Males and Females

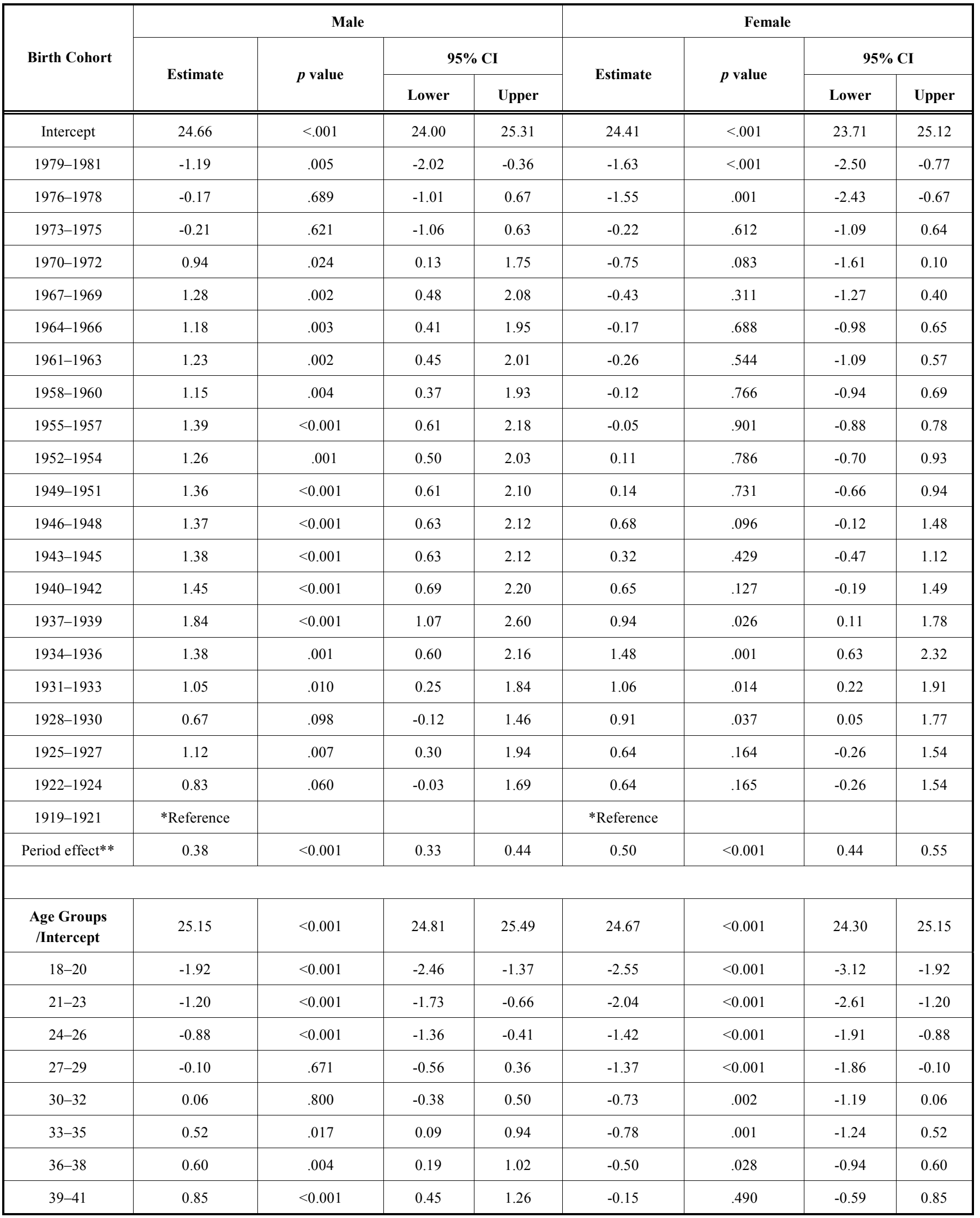


(Table 3) contd....

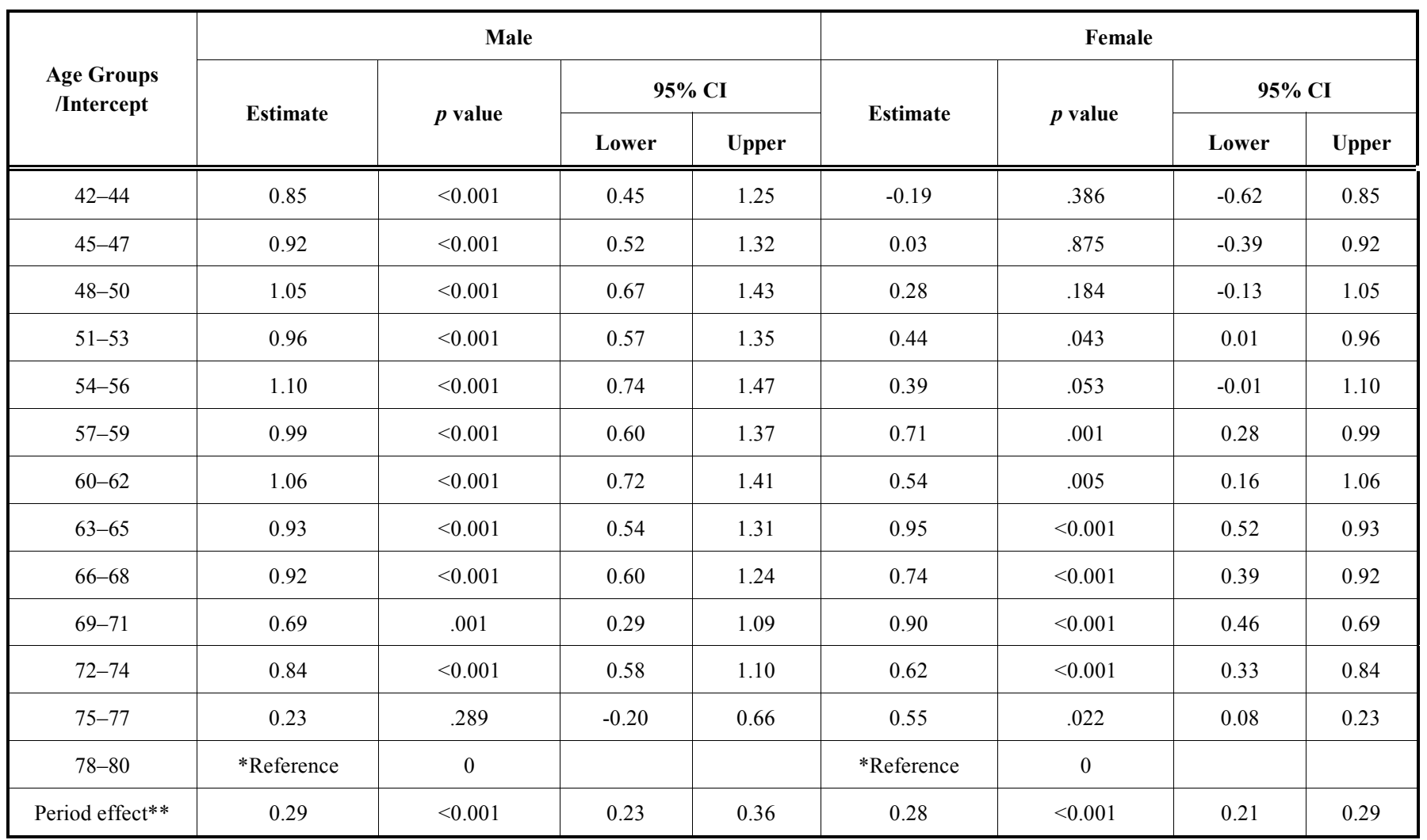

*Reference group in the models Period effect**: baseline 1999/2000 as a reference group

Cohort (left) and age (right) specific BMI change in males
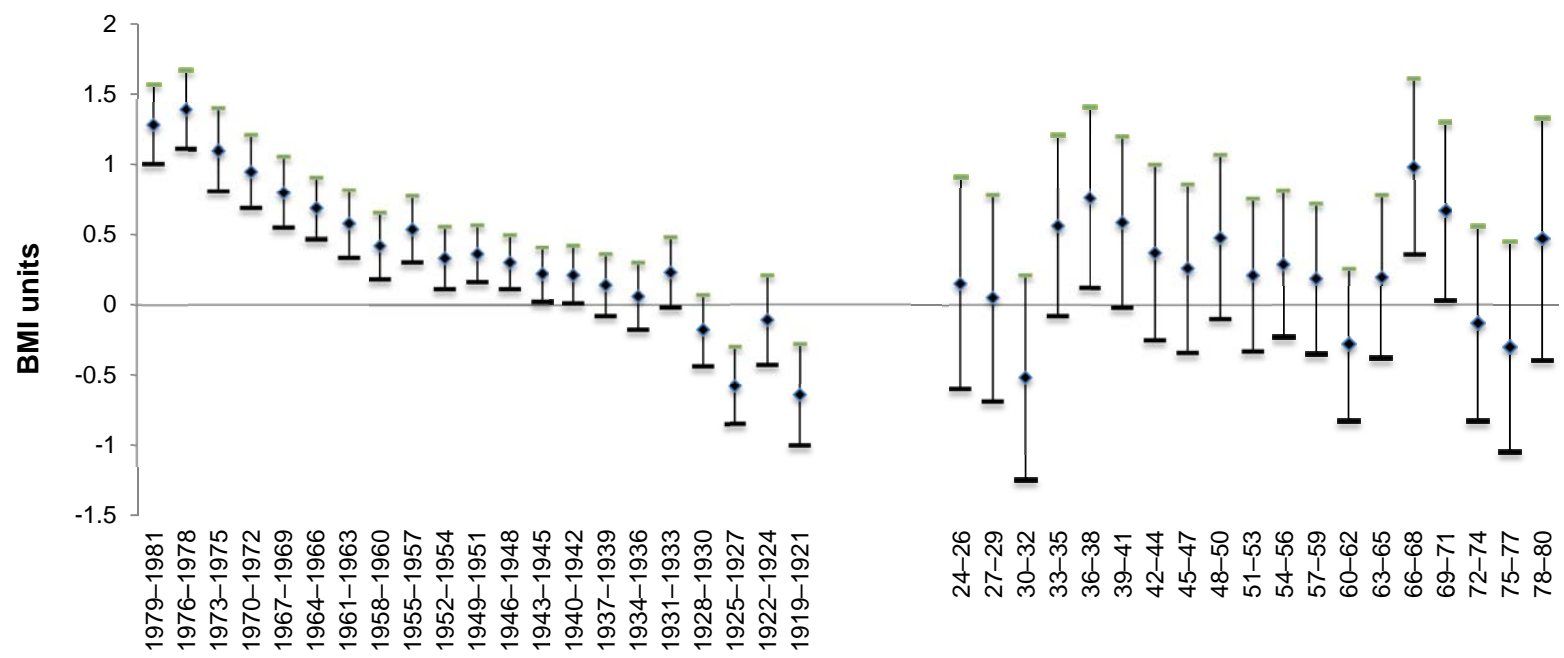

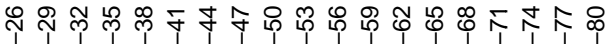

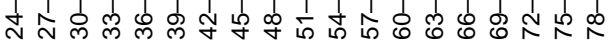

Fig. (1). Cohort- and age-specific changes in BMI from baseline (1999/2000) to follow-up (2005) (BMI units and 95\% CI) in males

In our Swedish study, the lack of a diverging pattern regarding cohorts born during WWII may be compared with findings in Dutch and Danish populations [42, 43].

The epigenetic theory would postulate an increase in BMI change for those born during WWII. Since this could not be verified in our study, we therefore conclude that our findings do not support the hypothesis of a epigenitically induced cohort effect in the general population in southern Sweden.

We believe the present study to be the first that analysis the population of a country not traumatized by direct warfare during this period, and whose population did not experience starvation or near-starvation. 


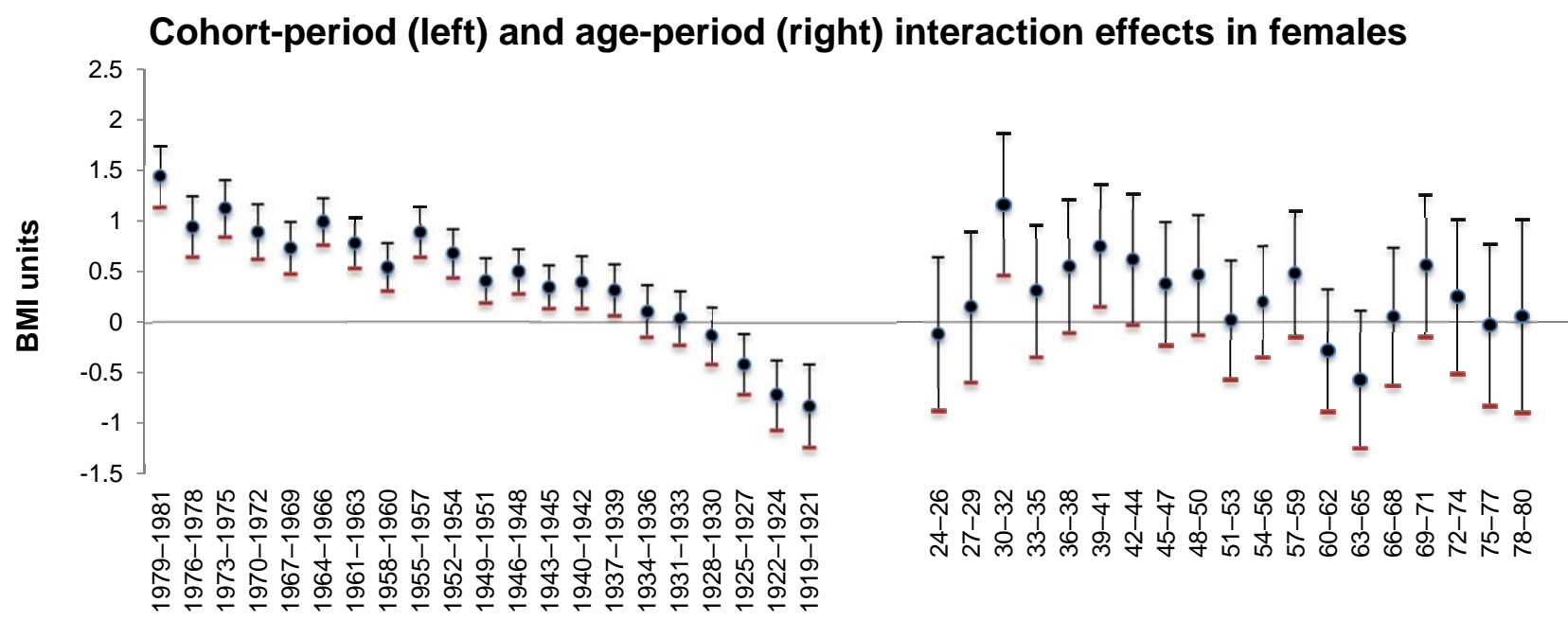

Fig. (2). Cohort- and age-specific changes in BMI from baseline (1999/2000) to follow-up (2005) (BMI units and 95\% CI) in females.

\section{STRENGTHS AND LIMITATIONS}

Our study has several advantages. First, it is longitudinal, prospective, and population-based, i.e., it examines changes in specific individuals. Second, it analyses a general population across all adult age groups, with baseline measurements ranging from ages 18 to 80 . This gave us the opportunity to analyse and compare the pattern of BMI change among a wide range of birth cohorts, whereas most previous studies have focused only on a specific age group or birth cohort, such as adult males or adult females. Third, it includes the study of older individuals ages 65 and above, thus presenting a more complete demographic picture of the overweight and obesity challenges in a high-income country. Fourth, to the best of our knowledge, it is the first attempt to separately evaluate age, period, and cohort effects on BMI trends between baseline and follow-up in a general Swedish population.

At the same time, we are aware of certain limitations. The response rate was $59 \%$ for the baseline assessment, which raises the issue of selection bias as an alternative explanation of our findings. However, the discrepancy in socio-demographic characteristics (level of education, income, and country of origin) between respondents and non-respondents has been investigated in a previous study [43], and showed the only difference to be a lower participation rate among individuals born outside Sweden. Moreover, health care utilisation during the year of the survey was very similar in both groups, indicating that a strong selection bias due to general status was improbable. Also, the BMI statistics we used were based on self-reported data, which may have contributed to an underestimation of overweight and obesity prevalence. Finally, another limitation in the method we chose is that it did not allow us to distinguish between age, period, and cohort effect within the same model. Holford (1991) suggested the approach in common use of estimating APC effects by applying a Poisson regression model. Unfortunately, since we only had two data points, this model would not have been appropriate. We have however, been able to disentangle age and cohort effect by applying age-period and cohort-period models, the same strategy was applied in several longitudinal studies [44, 45].

\section{CONCLUSION}

BMI increased during the five-year follow-up in most age groups. Our findings suggest that cohort effects may play a role in obesity, although those effects contradicted the epigenetic hypothesis. Moreover, these results suggest that it is difficult to distinguish between age-period and cohortperiod effects in our study, due to on the one hand the linear relationship between age, period and cohort, and on the other hand to short follow-up.

\section{CONFLICT OF INTEREST}

The author(s) confirm that this article content has no conflicts of interest.

\section{ACKNOWLEDGEMENT}

We thank the Swedish Council for Working Life and Social Research, grant number FAS 2005-1121, and the Erasmus Mundus program for supporting part of the Ph.D. fellowship under which this article was written.

\section{AUTHORS' CONTRIBUTIONS}

All the authors participated in the design of the study. FA-E and MS performed the statistical analyses in collaboration with JB and FA-E wrote the first draft of the manuscript. $\mathrm{P}-\mathrm{OÖ}$ was responsible for the data collection. P-OÖ, JB and MS commented on the draft versions of the manuscript. All authors read and approved the final manuscript.

\section{REFERENCES}

[1] Pedrosa C, Correia F, Seabra D, Oliveira BM, Simoes-Pereira C, Vaz-de-Almeida MD. Prevalence of overweight and obesity among 7-9-year-old children in Aveiro, Portugal: comparison between IOTF and CDC references. Public Health Nutr 2009; 14(1):1-6. 
[2] Rigby NJ, Kumanyika S, James WPT. Confronting the epidemic: the need for global solutions. J Public Health Pol 2004; 25(3/4): 418-34.

[3] WHO: Obesity and overweight (2011) Available from: [http://wwwwhoint/mediacentre/factsheets/fs311/en/\#] (accessed 8 August 2012).

[4] WHO. Golbal health risks: mortality and burden of disease attributable to selected major risks, 17-18. Available from: [http://wwwwhoint/healthinfo/global_burden_disease/GlobalHealth Risks_report_fullpdf] (accessed 10 September 2012).

[5] Astrup A. Macronutrient balances and obesity: the role of diet and physical activity. Public Health Nutr 1999; 2(Suppl 3a): 341-7.

[6] Jacoby E, Goldstein J, Lopez A, Nunez E, Lopez T. Social class, family, and life-style factors associated with overweight and obesity among adults in Peruvian cities. Prev Med 2003; 37(5): 396405 .

[7] Baecke JAH, Burema J, Frijters JER, Hautvast J, Vanderwielwetzels WAM. Obesity in young Dutch adults: II, daily life-style and body mass index (2007). Int J Obes 1983; 7(1):13-24.

[8] McLaren L. Socioeconomic status and obesity. Epidemiol Rev 2007; 29(1): 29-48.

[9] Stamatakis E, Primatesta P, Chinn S, Rona R, Falascheti E. Overweight and obesity trends from 1974 to 2003 in English children: what is the role of socioeconomic factors? Arch Dis Child 2005; 90(10): 999-1004.

[10] Becker S, Zimmermann-Stenzel M. Physical activity, obesity, and educational attainment in 50- to 70-year-old adults. J Public Health 2009; 17(2):145-53.

[11] Nyholm M, Gullberg B, Haglund B, Rastam L, Lindblad U. Higher education and more physical activity limit the development of obesity in a Swedish rural population. The Skaraborg Project. Int J Obes 2008; 32(3): 533-40.

[12] Eek F, Östergren P-O. Factors associated with BMI change over five years in a Swedish adult population. Results from the Scania Public Health Cohort Study. Scand J Public Health 2009; 37(5): 532-44.

[13] Sonestedt E, Gullberg B, Berglund G. Past food habit change is related to obesity, lifestyle and socio-economic factors in the Malmö Diet and Cancer Cohort. Public Health Nutr 2005; 8(7): 876-86.

[14] Greenblatt DJ, Abernethy DR, Locniskar A, Harmatz JS, Limjuco RA, Shader RI. Effect of age, gender, and obesity on midazolam kinetics. Anesthesiology 1984; 61(1): 27-35.

[15] Barker DJ, Hales CN, Fall CH, Osmond C, Phipps K, Clark PM. Type 2 (non-insulin-dependent) diabetes mellitus, hypertension and hyperlipidaemia (syndrome $\mathrm{X}$ ): relation to reduced fetal growth. Diabetologia 1993; 36(1): 62-7.

[16] Barker DJP, Eriksson JG, Forsen T, Osmond C. Fetal origins of adult disease: strength of effects and biological basis. Int J Epidemiol 2002; 31:1235-9.

[17] Rosmond R, Nilsson A, Björntorp P. Psychiatric ill health and distribution of body fat mass among female immigrants in Sweden. Public Health 2000; 114(1): 45-52.

[18] Sassi F, Devaux M, Cecchini M, Rusticelli E. The obesity epidemic: analysis of past and projected future trends in selected OECD countries. OECD Health Working Paper No. 45 2009; 23-5. Available from: [http://www.oecd-ilibrary.org/social-issuesmigration-health/the-obesity-epidemic-analysis-of-past-and-

projected-future-trends-in-selected-oecd-countries_225215402672] (accessed 8 September 2012).

[19] Glenn ND. Cohort Analysis, Quantitative Applications in the Social Sciences. Thousand Oaks CA: Sage Publications 1976.

[20] Fienberg SE, Mason WM. Specification and implementation of age, Period, and Cohort Models: Cohort Analysis in Social Research. New York: Springer-Verlag 1985.

[21] Mason KO, Winsborouch HH, Mason WM, Poole WK. Some methodological issues in cohort analysis of archival data. Am Sociol Rev 1973; 38: 242-58.
[22] Allman-Farinelli MA, Chey T, Bauman AE, Gill T, James WPT. Age, period and birth cohort effects on prevalence of overweight and obesity in Australian adults from 1990 to 2000. Eur J Clin Nutr 2007; 62(7): 898-907.

[23] Reither EN, Hauser RM, Yang Y. Do birth cohorts matter? Ageperiod-cohort analyses of the obesity epidemic in the United States. Soc Sci Med 2009; 69(10):1439-48.

[24] Olsen L, Baker J, Holst C, Sorensen T. Birth cohort effect on the obesity epidemic in Denmark. Epidemiology 2006; 17(3): 292-5.

[25] Kwon J-W, Song Y-M, Park Hye S, Sung J, Kim H, Cho S-I. Effects of age, time period, and birth cohort on the prevalence of diabetes and obesity in Korean men. Diabetes Care 2008; 31(2): 255-60.

[26] Nafziger AN, Stenlund H, Wall S. High obesity incidence in northern Sweden: how will Sweden look by? Eur J Epidemiol 2006; 21 : 377-82.

[27] Neovious M, Janson A, Rossner S. Prevalence of obesity in Sweden. Obes Rev 2006; $7: 1-3$.

[28] Bua J, Olsen LW, Sorensen TIA . Secular trends in childhood obesity in Denmark during 50 years in relation to economic growth. Obesity $2007 ; 15(4)$ : 977-85.

[29] Jacobsen BK, Njolstad I, Thune I, Wilsgaard T, Lochen M-L, Schirmer H. Increase in weight in all birth cohorts in a general population: the Tromso Study, 1974-1994. Arch Intern Med 2001; 161(3): 466-72.

[30] Lahti-Koski M, Jousilahti P, Pietinen P. Secular trends in body mass index by birth cohort in eastern Finland from 1972 to 1997. Int J Obes 2001; 25(5): 727-34.

[31] Diouf I, Charles MA, Ducimetière P, Basdevant A, Eschwege E, Heude B. Evolution of obesity prevalence in France: an age-periodcohort analysis. Epidemiology 2010; 21(3): 360-5.

[32] Lewis CE, Smith DE, Wallace DD, Williams OD, Bild DE, Jacobs Jr DR. Seven-year trends in body weight and associations with lifestyle and behavioral characteristics in black and white young adults: the CARDIA Study. Am J Public Health 1997; 87(4): 63542.

[33] Keyes K, Utz R, Robinson W, Li G. What is a cohort effect? Comparison of three statistical methods for modelling cohort effects in obesity prevalence in the United States, 1971-2006. Soc Sci Med 2010; 70(7):1100-8.

[34] Komlos J, Brabec M. The trend of mean BMI values of US adults, birth cohorts 1882-1986 indicates that the obesity epidemic began earlier than hitherto thought. Am J Hum Biol 2010; 22(5): 631-8.

[35] Launer LJ, Harris T, Rumpel C, Madans J. Body mass index, weight change, and risk of mobility disability in middle-aged and older women. JAMA 1994; 271(14): 1093-8.

[36] Nooyens AC, Visscher TL, Verschuren WM, et al. Age, period and cohort effects on body weight and body mass index in adults: the Doetinchem Cohort Study. Public Health Nutr 2009; 12(6): 862-70.

[37] Swinburn BA, Sacks G, Hall KD, et al. The global obesity pandemic: shaped by global drivers and local environments. Lancet 2011; 378(9793): 804-14.

[38] Gortmaker SL, Swinburn BA, Levy D, et al. Changing the future of obesity: science, policy, and action. Lancet 2011; 378(9793): 83847.

[39] French SA, Harnack L, Jeffery RW. Fast food restaurant use among women in the Pound of Prevention study: dietary, behavioral and demographic correlates. Int J Obes Relat Metab Disord 2000; 24(10):1353.

[40] Ludwig DS, Pollack HA. Obesity and the economy. JAMA 2009; 301(5): 533-5.

[41] Thomsen BL, Ekstrom CT, Sorensen TIA. Development of the obesity epidemic in Denmark: cohort, time and age effects among boys born 1930-1975. Int J Obes 1999; 23(7): 693-701.

[42] Ravelli AC, van der Meulen JH, Osmond C, Barker DJ, Bleker OP. Obesity at the age of 50 years in men and women exposed to famine prenatally. Am J Clin Nutr 1999; 70(5): 811-6. 
[43] Carlsson F, Merlo J, Martin L, Östergren P-O, Lithman T. Representativity of a postal public health questionnaire survey in Sweden, with special reference to ethnic differences in participation. Scand J Public Health 2006; 34(2):132-9.
[44] Bae K-K, Kim H, Cho S-I. Trends in Body Mass Index and Associations With Physical Activity among career soldiers in South Korea. J Prev Med Public Health 2011; 44(4): 167-75.

[45] O'Brien RM, Hudson K, Stockard J. A Mixed model mstimation of age, period, and cohort effects. Sociol Meth Res 2008; 36(3): 40228 .

Received: June 06, 2013

Revised: July 27, 2013

Accepted: July 28, 2013

(C) Al-Emrani et al.; Licensee Bentham Open.

This is an open access article licensed under the terms of the Creative Commons Attribution Non-Commercial License (http://creativecommons.org/licenses/by-nc/3.0/) which permits unrestricted, non-commercial use, distribution and reproduction in any medium, provided the work is properly cited. 